\title{
Genética y biotecnología precolombina
}

DOI: $10.46932 / \mathrm{sfjdv} 2 \mathrm{n} 1-004$

Received in: November 1st, 2020

Accepted in: December 30th, 2020

\author{
Mario Ramón Ruiz De Castilla Marín (1) \\ Centro de Investigación Multidisciplinario de Catedráticos Cesantes de la UNSAAC. \\ Cusco, Perú. \\ E-mail: mariordcm@yahoo.es
}

\section{RESUMEN}

Se analiza el proceso de domesticación de animales y plantas realizado por los antiguos peruanos, que en su evolución cultural, su lucha por la sobrevivencia y por el dominio de la naturaleza lograron el cambio genético de las especies silvestres manejando la genética y la biotecnología desde tiempos remotos. La domesticación en Los Andes culminó con la creación de más de 150 plantas cultivadas y 5 animales domésticos (llama, alpaca, cuy, pato criollo y perro sin pelo del Perú).

Para la formación de la base genética los genetistas precolombinos sabían que era necesario tener una población con alta variabilidad genética para lograr un satisfactorio cambio genético. Utilizaron la Selección, para lo que emplearon sistemas de identificación de los animales, dividiendo los rebaños por sexo, edad y color de la fibra en camélidos. Supieron elegir y priorizar los caracteres de interés económico y biológico. Emplearon la selección fenotípica, escogiendo individuos sobresalientes y realizando apareamientos entre los mejores animales. Manejaron la consanguinidad para fijar caracteres y la heterosis para aprovechar el "vigor híbrido" de la descendencia. Utilizaron la clonación o propagación asexual de las plantas cultivadas. Manejaron los cambios zonales repentinos de los tejidos (quimeras) como fuente de variabilidad. Inventaron los sistemas de conservación de alimentos por deshidratación (liofilización). Se concluye que los genetistas precolombinos conocieron y aplicaron la genética y la biotecnología en la domesticación de plantas y animales, así como en la conservación de alimentos.

Palabras clave: Genética, biotecnología, domesticación.

\section{SUMMARY}

The process of domestication of animals and plants carried out by the ancient Peruvians is analyzed, who in their cultural evolution, their struggle for survival and for the domination of nature achieved the genetic change of wild species, managing genetics and biotechnology since remote times. Domestication in the Andes culminated in the creation of more than 150 cultivated plants and 5 domestic animals (llama, alpaca, guinea pig, creole duck and Peruvian hairless dog).

For the formation of the genetic base, pre-Columbian geneticists knew that it was necessary to have a population with high genetic variability to achieve a satisfactory genetic change. They used the Selection, for which they used animal identification systems, dividing the herds by sex, age and fiber color in camelids. They knew how to choose and prioritize the characters of economic and biological interest. They used phenotypic selection, choosing outstanding individuals and mating among the best animals. They handled consanguinity to set characters and heterosis to take advantage of the "hybrid vigor" of the offspring. They used asexual cloning or propagation of cultivated plants. They handled sudden zonal tissue changes (chimeras) as a source of variability. They invented food preservation systems by dehydration (lyophilization).

\footnotetext{
${ }^{1}$ Ingeniero Zootecnista. Investigador Egresado de la Maestría en Producción Animal por la Universidad Nacional Agraria La Molina, Lima, Perú.
} 
It is concluded that pre-Columbian geneticists knew and applied genetics and biotechnology in the domestication of plants and animals, as well as in food preservation.

Keywords: Genetics, biotechnology, domestication.

\section{INTRODUCCIÓN}

La vida en La Tierra aparece hace 3.500 millones de años, iniciando la evolución de animales y plantas. En este proceso evolutivo, las especies han ido experimentando cambios genéticos en forma natural, mediante los mecanismos de la herencia y la variación genética.

El hombre en procura de satisfacer sus necesidades primarias, especialmente de alimentos, ha intervenido en la evolución desde hace 9.000 a 10.000 años, con la creación de nuevos genotipos de animales y plantas mediante la domesticación.

En las montañas de los Andes el hombre encontró un emporio de variabilidad genética, debido a la diversidad de ambientes condicionada por su topografía accidentada y la presencia de nichos ecológicos en los que existen comunidades vegetales muy diversas y una abundante fauna.

Esta diversidad biológica ha sido favorecida en las altas montañas por la intensa radiación solar, que es un poderoso agente de mutaciones y por el efecto aislante de las barreras físicas como los nevados.

\section{OBJETIVO}

Explicar e interpretar, bajo la lógica de los conocimientos científicos actuales, la utilización de la genética y la biotecnología en el proceso de domesticación de animales por el hombre andino desde hace aproximadamente 10.000 años.

\section{MATERIALES Y MÉTODOS}

Se ha empleado la investigación documental, apoyada en la fuente bibliográfica y hemerográfica basada en la consulta de libros, artículos y ensayos publicados sobre la domesticación y la genética. Se trata de una investigación explicativa en la que se analizan los sucesos y partiendo de este análisis llevar a cabo la síntesis que reconstruya y explique los métodos y procedimientos empleados por los antiguos andinos en la domesticación de animales.

\section{RESULTADOS Y DISCUSIÓN}

Probablemente el Hombre de Paccaycasa (22.000 años a.C.), el hombre más antiguo del Perú, para subsistir aprovechó directamente los frutos de la naturaleza, pero los peruanos de hace 8 a 10 mil años empezaron a apropiarse de los recursos genéticos animales y vegetales. La captura y cría de animales 
jóvenes y la observación y replicación de la multiplicación vegetal a partir de semillas caídas al azar, fueron seguramente los primeros pasos hacia la domesticación.

\subsection{LA DOMESTICACIÓN}

La domesticación es un proceso evolutivo dirigido por el hombre para la creación de nuevos genotipos a partir de poblaciones de animales silvestres, por medio de modificaciones hereditarias, para la satisfacción de las necesidades humanas.

Lo admirable de este proceso es que a pesar de la escasez de recursos materiales y la carencia de una base teórico científica de biología, genética, biometría y otras ciencias y tecnologías y solo con intuición y mucha creatividad, el hombre andino logró estos cambios genéticos.

Él modeló las especies a su voluntad, hizo sus creaciones contradiciendo las leyes de la selección natural y de la evolución. Ejemplos de objetivos de la domesticación antagónicos a los de la supervivencia de las especies son: el mayor tamaño y peso corporal de la llama y la alpaca en comparación a la vicuña, su antecesora silvestre, cuyo menor tamaño y agilidad la protegen de los predadores, los colores atractivos de alpacas y llamas a diferencia del color canela de los guanacos y vicuñas que se mimetizan en la pradera altoandina.

Lo que se buscó con la domesticación de los animales fue la capacidad de reproducirse en cautiverio; la docilidad, el mayor tamaño y fuerza de trabajo para el transporte de carga en la llama; tamaño, finura y color de la fibra en la alpaca; y el rendimiento y calidad de la carne en el cuye y las llamas de biotipo cárnico. La aparición del Perro sin pelo del Perú (Canis lupus familiaris) probablemente ocurrió por una mutación genética del lobo Canis dirus. Su domesticación empezó el 7.000 a.C. en Jaywamachay, Ayacucho. Se lo utilizó como alimento humano.

La domesticación de la llama (Lama glama) y la alpaca (Vicugna pacos) ocurrió en el Arcaico Temprano 7.000 a.C. en Telarmachay (Junín), a partir del guanaco (Lama guanicoe) y la vicuña (Vicugna vicugna), respectivamente.

El hombre de Telarmachay domesticó el cuy (Cavia porcellus), entre 5.000 a.C. a 3.700 a.C. en Junín a partir de la especie silvestre Cavia tschudii (poronccoy). Hacia el Formativo fue domesticado el pato criollo (Cairina moschata) por los genetistas de la cultura Chavín (2.000 a.C. a 200 a.C.) a partir del pato amazónico.

\subsection{ANÁLISIS DE LOS MÉTODOS Y PROCEDIMIENTOS EMPLEADOS EN LA DOMESTICACIÓN Y MEJORAMIENTO GENÉTICO DE ANIMALES POR LOS ANTIGUOS PERUANOS}

En la formación de la base genética, los hombres precolombinos sabían que para lograr un satisfactorio cambio genético se requiere de una población con alta variabilidad genética, para ello eligieron animales de diferentes lugares geográficos de los Andes Centrales. Utilizaron la Selección, para lo que emplearon sistemas de identificación de los animales, dividiendo los rebaños por sexo, edad y color de la fibra en camélidos. 
Supieron elegir y priorizar los caracteres de interés económico y biológico; sabían que el cambio genético por generación es más rápido si se eligen pocos caracteres en el proceso de selección. Emplearon la selección fenotípica, escogiendo individuos sobresalientes y realizando apareamientos entre los mejores animales. Hoy se sabe que este proceso acumula genes aditivos responsables del rendimiento en peso corporal y peso de vellón, vigor y adaptabilidad al ambiente, y fija genes mayores que controlan el color de la fibra, permitiendo al mismo tiempo la adaptabilidad y la invariabilidad del tipo.

Tipos de selección utilizados: El tipo más utilizado fue la selección direccional orientada a la maximización de un determinado carácter, por ejemplo, tamaño grande del animal. Se usó también la selección estabilizante cuyo objetivo es producir materiales intermedios como por ejemplo, la variedad intermedia de llamas. Por último, la selección disruptiva llega a la creación de dos tipos opuestos, como es el caso de las alpacas Suri y Wacaya.

Manejaron la consanguinidad para fijar caracteres mediante técnicas de aislamiento de rebaños de alpacas y llamas. Conocieron los efectos negativos de la consanguinidad, descubrieron los indicadores de la consanguinidad en cuyes, como los dedos supernumerarios (t'ata) o las orejas cortas (chunu). Conocieron los síntomas de la depresión consanguínea (disminución de la producción, pérdida de prolificidad, esterilidad y frecuencia de abortos). En cuyes se evitaba la consanguinidad mediante el cambio de reproductores propios con otros de colores y tipos de pelaje diferentes.

Emplearon la heterosis para aprovechar el "vigor híbrido" de la descendencia apareando animales de distintos linajes, hoy se conoce que produce un aumento notable en la producción de la progenie.

Para la introducción de material genético nuevo se efectuaba una primera crianza aislada de animales, luego se evaluaba su adaptabilidad y para la creación del tipo final se realizaban cruzamientos dirigidos.

Conocieron la sexualidad y su importancia genética.

\subsection{APLICACIONES DE LA BIOTECNOLOGÍA}

Los antiguos peruanos, inventaron los sistemas de conservación de alimentos por deshidratación (liofilización). La liofilizanción se utilizó en la carne de llamas y alpacas para la elaboración del charqui, en papas para la elaboración del chuño y la moraya, en ocas para elaborar la khaya y la unukhaya y en el olluco para el linli. Los fundamentos físicos de estas prácticas ancestrales pueden ser explicados mediante el efecto del congelamiento de los tubérculos, que rompe las paredes celulares o por lo menos extrae el agua intracelular por ósmosis, lo que facilita la extracción posterior del líquido. En lo referente al salado de las carnes, aumenta notablemente la presión osmótica de tal forma que las células pierden toda su agua por plasmólisis, pereciendo. Los bajos contenidos de humedad de los sustratos, por su parte, impiden también el establecimiento de microorganismos y detienen los procesos enzimáticos.

Utilizaron la clonación o propagación asexual de las plantas cultivadas, empleando órganos vegetativos: tubérculos, rizomas, tallos, etc., en lugar de las verdaderas semillas. Manejaron los cambios zonales repentinos de los tejidos (quimeras) como fuente de variabilidad. En las ocas, 
por ejemplo, se puede observar que en una variedad de tubérculos amarillos aparecen algunos jaspes rosados, si algún ojo está localizado en plena mancha rosada, las yemas que se originen en él producirán plantas con tubérculos rosados en lugar de amarillos

\section{CONCLUSIÓN}

Los genetistas precolombinos andinos conocieron y aplicaron la genética y la biotecnología en la domesticación de plantas y animales, así como en la conservación de alimentos. 


\section{REFERENCIAS}

ACOSTA, J. 1962/1590. Historia Natural y Moral de las Indias. Fondo de Cultura Económica, México.

ANGULO, C. Enrique, G. 1998. Interpretación biológica acerca de la domesticación del pato criollo (Cairina moschata). Bull. Inst. Fr. Études Andines 27 (1):17-40.

ANTUNEZ DE MAYOLO, S. E. 2011. La Nutrición en el Antiguo Perú. $6^{a}$ ed. Sociedad Geográfica de Lima. 240 p.

ARTIGAS, M; TURBON, D. 2008. El origen del hombre. Ciencia, filosofía y religión. $3^{\circ}$ edición EUNSA. Pamplona

BACHIR BACHA, A; LLANOS J. O. D. 2012. Arqueología e iconografía de los textiles Paracas descubiertos en Ánimas Altas, Ica, Perú. In: Solanilla, Victoria (Hg.): Actas de las V Jornadas Internacionales sobre Textiles Precolombinos. Publicaciones del Grup d'Estudis Precolombins 6. Barcelona: Universidad Autónoma de Barcelona, S. 211-230

BARREDA, L. 1994. Historia y Arqueología Pre-Inka. Instituto de Arqueología Andina Machupicchu. Cusco. Perú. 92 pp.

BETANZOS, J. de. 1999/1551. Suma y Narración de los Incas. Re-edición. Fondo Editorial de la UNSAAC.

BOTIGUE L. R. et al. 2017. Ancient European dog genomes reveal continuity since the Early Neolithic. Nature Communications, 18 de julio de 2017. DOI: 10.1038/ncomms 16082

CABEZA DE BACA, A. 1852 (1555). Comentarios. In Historiadores primitivos de indias (E. Vedia, dir.): 549-599; Madrid: Imprenta y estereotipia de M. Rivadeneyra.

CIEZA DE LEÓN, P. 1553 (1967). Crónica del Perú (Capítulos XCIC-CXXI).

COBO, B. 1653 (1958). Historia del Nuevo Mundo. Biblioteca de Autores Españoles. Madrid.

COMMITTEE ON GRAND RESEARCH QUESTIONS IN THE SOLID-EARTH SCIENCES, NATIONAL RESEARCH COUNCIL. 2008. Origin and Evolution of Earth: Research Questions for a Changing Planet, The national academies press (Prepub).

CHATTERS, J. C. et al. 2014. Late Pleistocene Human Skeleton and mtDNA Link Paleoamericans and Modern Native Americans. Revista Science volumen 344 (16 de mayo de 2014), página 750.

ENGEL, F. 1966. Paracas, cien siglos de cultura peruana. Librería editorial Juan Mejía Baca. Lima. Perú FAO. 2005. Lista mundial de vigilancia para la diversidad de los animales domésticos. Roma.

FLORIAN J. A. et al. 2018. Convergent genomic signatures of domestication in sheep and goats. Nature Communications 6 de marzo de 2018

GARCILASO, INCA DE LA VEGA. 1609 (1959). Comentarios reales de los Incas. Universidad Mayor de San Marcos. Lima. 
GILMORE, R. M. 1950. Fauna and ethnozoology of South America. In: Handbook of south American Indians, Vol. 6 ( J.H. Steward ed.) 365-464; Washington: Smithsonian Institution.

GONZALES CARRÉ, E. 2007. Historia prehispánica de Ayacucho. Tercera Edición. Lluvia Editores. $138 \mathrm{pp}$.

HAINES, T.; CHAMBERS, P. 2006. The Complete Guide to Prehistoric Life. Pg. 176. Canada: Firefly Books Ltd.

HARARI, Y. N. 2016. De animales a Dioses. Breve historia de la humanidad. Penguin Random House. Grupo editorial Mexico DF.

HARE, B. et al. 2012. La hipótesis de la autodomesticación: evolución de la psicología bonobo. Elsevier Ltd.

IMMELMANN, K. 1980. Introduction to ethology. Ed. Plenum press. New York. USA

KAULICKE, P. 2010. Las cronologías del Formativo. 50 años de investigaciones japonesas en perspectiva. Lima: Fondo Editorial de la Pontificia Universidad Católica del Perú

LOPEZ, N. 2007. La dinámica de la evolución humana. Más con menos. EUNSA, Pamplona

LAVALLÉE, D. 1990. La domestication animale en Amerique du Sud. En Bulletin de I'Institut Francais d Estudes Andines, n 19, pp. 25-44. Lima.

LUMBRERAS, L. G. 2005. Arqueología y Sociedad. IEP ediciones. Lima. Perú. 320 pp.

MÄCHTLE, B.; EITEL, B. 2013. Fragile landscapes, fragile civilizations - How climate determined societies in the pre-Columbian south Peruvian Andes. In: Catena, 103: 62-73.

MOREIRA, L.S. et al. 2013. Holocene paleoenvironmental reconstruction in the Eastern Amazonian Basin: Comprido Lake. In Journal of South American Earth Sciences. v.44, 55-2

RANGE, F; VIRÁNYI, Z. 2013. Rastreando los orígenes evolutivos de la cooperación perro-humano. La hipótesis de la cooperación canina. Publicado en línea 15 de enero de 2015. DOI: 10 3389/fpsyg. 2014.01582

REINDEL, M. ISLA, J. 2013. Cambio climático y patrones de asentamiento en la vertiente occidental de los andes del sur del Perú. Diálogo Andino - Revista de Historia, Geografía y Cultura Andina [en linea] 2013, (Junio-Sin mes): [Fecha de consulta: 5 de febrero de 2019] Disponible en:<http://www.redalyc.org/articulo.oa?id=371334532006> ISSN 0716-2278

RUIZ DE CASTILLA, M. 1994. Camelicultura. Alpacas y llamas del sur del Perú. Municipalidad del Qosqo. Editorial Mercantil EIRL. Cusco. 206 pp.

RUIZ DE CASTILLA, M. 2004. Genética y mejoramiento de animales domésticos. Editorial universitaria Universidad Nacional de San Antonio Abad del Cusco. Cusco. Perú. 286 pp. 
RUIZ DE CASTILlA, M. 2006. Domesticación y Persistencia de los Camélidos en los Andes de Cusco. Instituto Nacional de Cultura. Danny's Graff. Cusco. 88 pp.

SHADY, R; LEYVA, C. 2003. La ciudad sagrada de Caral-Supe. Los orígenes de la civilización andina y la formación del Estado prístino en el antiguo Perú. INC. Lima. Perú. 342 pp.

WHEELER, J. C. 1984. La domesticación de la alpaca (Lama pacos) y la llama (Lama glama) y el desarrollo temprano de la ganadería autóctona en los Andes Centrales. Boletín de Lima. 36:74-84.

WING, E., 1977. Animal Domestication in the Andes. In C.A. Reed (ed), Mouton Publishers, The Hague, pp. 837-859.

ZAMORA, A. F. 2013. Primera reconstrucción paleoclimática cuantitativa: del polen de madriguera al clima del pasado en un transecto altitudinal del altiplano de Chile, pozo almonte-salar del Huasco. Región de Tarapacá. Monografía. Universidad de Chile. Santiago. Chile. 